\title{
De silencios, amnesias y mentiras
}

Jerónimo López Mozo o el compromiso con la memoria

\section{Antonia Amo Sánchez}

\section{OpenEdition}

\section{Journals}

Edición electrónica

URL: https://journals.openedition.org/cher/331

DOI: $10.4000 /$ cher.331

ISSN: 2803-5992

\section{Editor}

Presses universitaires de Strasbourg

\section{Edición impresa}

Fecha de publicación: 19 noviembre 2020

Paginación: 57-76

ISBN: $979-10-344-0071-3$

ISSN: 1968-035X

Referencia electrónica

Antonia Amo Sánchez, «De silencios, amnesias y mentiras», reCHERches [En línea], 25 | 2020,

Publicado el 01 octubre 2021, consultado el 22 noviembre 2021. URL: http://journals.openedition.org/ cher/331 ; DOI: https://doi.org/10.4000/cher.331 


\title{
De silencios, amnesias y mentiras Jerónimo López Mozo o el compromiso con la memoria
}

\author{
ANTONIA AmO SÁNCHEZ ${ }^{1}$
}

\begin{abstract}
Terónimo López Mozo (1942) pertenece a una constelación de autores que desde los años '90 desarrollan una dramaturgia volcada en la recuperación de la memoria histórica reciente española. Identificados bajo la mención "Generación de los nietos", en este grupo abanderado por autores del calibre de Juan Mayorga, Gracia Morales, Itziar Pascual o Laila Ripoll, destacan igualmente autores curtidos por edad y por experiencia, como Alberto Miralles, Antonio Martínez Ballesteros, Miguel Murillo o el dramaturgo al que aquí dedicamos estas páginas.

Si los manuales de historia del teatro español contemporáneo identifican a López Mozo con la llamada Generación simbolista (o Underground o del "nuevo teatro") de los años '60/'70, la diversificación de géneros, lenguajes y estéticas que caracterizan la trayectoria artística del autor hacen imposible acotar su teatro en función de una única corriente artística. Así, existe una línea de su teatro que, más allá del simbolismo estilizado, del happening o del teatro documento característicos de las escrituras teatrales de los ' $60 /{ }^{\prime} 70$, se adscribe al realismo social, de marcados tintes buerianos tanto como brechtianos, y está también influenciada por los importantes aportes de la tradición áurea genuinamente española.
\end{abstract}

\section{«La trilogía de la memoria » o el teatro que rompe con el pacto del silencio}

Tres son las obras que Jerónimo López Mozo agrupa en lo que el propio autor así como la crítica tienen a bien denominar el "tríptico de la memoria histórica", compuesto por El arquitecto y el relojero, El olvido está lleno de memoria y Las raíces cortadas. Las tres obras siguen el surco de un compromiso crítico y político que desde siempre ha impregnado el quehacer ético y artístico de Jerónimo López Mozo. Si ya en los últimos ‘60 el contexto de represión y censura inspiraba

1 Maîtresse de conférences, HDR, Université d'Avignon (ICTT). 
una escritura combativa con la que firmó obras de temática histórica como Anarchia 36 (1970) o Guernica (1975), esta misma escritura no perderá vigor en los '80 y '90, desplazando los temas hacia el cuestionamiento de la conquista y colonización de las Américas (Yo, maldita india, 1990) y hacia la revisión crítica de la transición democrática. Esta temática alimenta el planteamiento dramático de las tres obras mencionadas, pautadas también por un perspectivismo activo que teje puentes directos entre el ayer y el hoy: el pasado interesa no solo en tanto que substrato referencial de problemáticas colectivas inacabadas, sino también como materia de reflexión filosófica y ontológica. El hombre, pues, en su devenir histórico, pero también en su esencia existencial. Veremos cómo estas obras se concentran sobre todo en el valor del legado de un pasado imperfecto, en el doble sentido de la palabra: inacabado y por ello perfectible. En este sentido, a la pregunta sobre la vigencia y alcance de la dramaturgia de la memoria histórica, López Mozo apunta sin ambages el carácter insoslayable del subgénero en el panorama teatral español contemporáneo en tanto que, desde los ' 90 , responde a una situación político-social no zanjada, todavía hoy generadora de controversia y enfrentamiento. En estos términos lo expone el propio López Mozo:

[El teatro de la memoria histórica] ocupa un lugar importante en la producción de estos años. Bastante más, desde luego, que en los años de la Transición. En mi opinión, el cambio empezó a producirse cuando los herederos de las víctimas de la guerra civil empezaron a exigir su rehabilitación y la anulación las sentencias dictadas durante la posguerra por los tribunales de justicia del régimen franquista y, sobre todo, que se emprendiera la búsqueda de fosas comunes para devolverles los restos de los familiares enterrados en ellas. El hecho de que los poderes públicos no atendieran esas demandas o lo hicieran con tibieza destapó una ola de solidaridad que movilizó a sectores de izquierdas y grupos inquietos de nuestra sociedad. Su reflejo en los medios de comunicación y la actuación de determinados jueces progresistas que dieron importantes pasos para la reparación de los daños causados durante la guerra y primeros años de la dictadura han permitido mantener viva esa lucha. Los creadores han aportado su grano de arena y muchas de sus obras tienen que ver con todo cuanto cabe bajo el paraguas de la memoria histórica. La bibliografía de obras de ficción o que recrean hechos reales es notable. En el campo concreto del teatro no es una excepción (López Mozo $12 / 09 / 2013)^{2}$

En su posicionamiento sobre la problemática de la memoria, López Mozo denuncia la ausencia de una cultura de la memoria desde los años '80; asignatura pendiente de la sociedad española retomada por las nuevas generaciones que no dudan en reanudar con un teatro comprometido con la revisión de las nociones de verdad y justicia históricas:

2 A principios del mes de septiembre de 2013 invitamos a una serie de autores, entre ellos Jerónimo López Mozo, a responder por escrito a una encuesta sobre el valor del teatro de la memoria para trabajar contra la mentira histórica. Nuestro más sincero agradecimiento al autor por su apreciada colaboración. La entrevista se publica al final del presente artículo. 
La solución a estas cuestiones avanza con gran lentitud. Las trabas de los que se resisten a revisar nuestro pasado y a reconocer la verdad histórica son enormes. Está todavía lejos el momento en que se haga justicia y las heridas cicatricen. En consonancia con ello, el de la memoria histórica, es un asunto que seguirá presente en la literatura actual. Es necesario que así sea. ¿Hasta cuándo? Al menos, hasta que el tema quede definitivamente cerrado, pero muy probablemente siga siendo motivo de reflexión durante algún tiempo más. Me lleva a pensar así que, con la incorporación de nuevos dramaturgos, el interés no ha decaído. Hablo del teatro, que es el medio que mejor conozco. Veo como jóvenes colegas abordan estos temas pertenecientes a un pasado que para algunos empieza a ser remoto (López Mozo 12/09/2013).

En cuanto a la naturaleza y reacción del público atraído por este teatro a las claras político, López Mozo aplaude la diversidad generacional del público que acude a las salas, puntualizando, no obstante, el evidente cambio de ethos respecto al público de los ' 80 , años en los que los artistas «más que público pedíamos cómplices», retomando las palabras de Alberto Miralles (Miralles 1982). López Mozo subraya la compatibilidad hoy de lo minoritario con lo necesario: en efecto, nos hallamos ante una dramaturgia de difícil incursión en las escenas públicas nacionales, pero que encaja bien en los canales alternativos donde acude un público con cierta sensibilidad política, un público ávido también por (re)descubrir otras visiones o lecturas del pasado:

[...] el teatro al que nos estamos refiriendo es minoritario. Minoritario, pero necesario. No tiene gran capacidad de convocatoria en la escena comercial, pero no es despreciable el número de personas que se sienten atraídas por él. Su espacio natural son las salas alternativas. Sobre el público interesado en la memoria histórica debo decir que, en lo que a mí respecta, me siento satisfecho con su respuesta. No es exaltada, como sucedía durante el franquismo y primeros años de la transición, cuando el teatro comprometido cumplía, además de su función artística, la de servir de tribuna política. La complicidad entre creadores y receptores no se exterioriza ahora de la misma manera. Hoy, los ciudadanos tienen muchos más cauces para expresarse y desahogarse. Pero la comunión con el público se mantiene. Puedo dar fe de ello. En las representaciones a las que he asistido de mis propias obras he vivido momentos conmovedores. En una representación de Guernica en Nueva York, una anciana me contó que había nacido en esa ciudad y había sufrido su bombardeo. En otros casos he visto llorar a espectadores ancianos que vivieron los años de la República y la Guerra Civil y muchos, al saber que yo estaba entre el público, me han buscado para abrazarme y contarme cómo vivieron ellos aquel período. En una representación de Las raíces cortadas en el Ateneo de Madrid fui obsequiado con un ramo de flores cuyos colores reproducían la bandera republicana. Pero, a este emotivo archivo de la nostalgia, se añade otro alimentado por gente joven que no solo no vivió aquella etapa, sino que poco o nada sabía de lo sucedido en ella. Despertar su interés es uno de los objetivos de la recuperación de la memoria histórica. La respuesta recibida me anima a seguir empeñado en esa tarea (López Mozo 12/09/2013).

Por otro lado, López Mozo denuncia también cómo los dramaturgos de su generación, y sobre todo los incluidos en la Generación simbolista, fueron 
"víctimas" de varios tipos de silencio a que la coyuntura político-cultural de los años '70 y ' 80 se obstinó en relegarlos. Por un lado, un silencio represivo al que les sometió la censura; por otro lado, un "ninguneo" institucional y cultural sufrido durante la transición, en la cual la llamada "operación restitución" de estos artistas "malditos" no consiguió rendirles el homenaje o el reconocimiento debido (López Mozo 1999; Vilches de Frutos 2011). Por forzada que parezca nuestra lectura a raíz de estas circunstancias, no deja de tener sentido que un autor como López Mozo, apolítico por convicción, pero aun así militante, sufridor de silencios, pero aun así constante activista de la palabra, inculque en sus obras sobre la memoria histórica un especial sentido de la justicia histórica: reclamo de justicia ante la necesidad de reconocimiento (algo que caracteriza muy claramente a los personajes de sus obras El olvido está lleno de memoria y Las raíces cortadas).

El teatro de la memoria histórica de López Mozo se inserta de lleno en el nuevo canon poético con el que se declina esta dramaturgia a partir de los ' 90 . Ajena al mero aspecto documental, esta escritura no persigue, como lo explicara en su día Wilfried Floeck, una restitución convencionalista de la historia ni un "borrón y cuenta nueva" globalmente tipificado en el teatro de la memoria de los últimos '70/'80, hasta el advenimiento de ¡Ay, Carmela! de José Sanchis Sinisterra (Floeck 2006). El teatro de la memoria de López Mozo, como el de Laila Ripoll, Itziar Pascual, Gracia Morales, Juan Mayorga o Alberto Miralles, por citar a algunos, es militante y crítico, marcado por una poética de la memoria renovada, que logra asentar las bases de una dramaturgia a carta cabal, que en otro lugar hemos llamado "dramaturgia de lo imprescriptible" (Amo Sánchez 2014). Con todo, se identifica López Mozo con una posición más humanística que política en tanto en cuanto el teatro puede o debe proponer también una "reparación" y/o dignificación de lo humano ante los agravios cometidos por los victimarios hacia las víctimas. Así pues, nos hallamos ante una dramaturgia en la que se combina lo "recordativo", como declinación etimológica (recordare: pasar dos veces por el corazón) de una memoria emotiva y sentimental que definiera en su día al teatro de la memoria de Fernando Fernán Gómez en su obra Las bicicletas son para el verano, y lo "recuperativo". Las miradas "regresativas" (neologismo de Miguel Hernández) de los '80, adoptan, en la dramaturgia de los ' 90 , un enfoque absolutamente político y comprometido - reparativo -, en el que cada autor aporta su estética propia. Como la mayoría de los dramaturgos de lo imprescriptible, también López Mozo trabaja un realismo anti-ilusionista, poblado de apariciones fantasmales, recursos oníricos o metamemoriales, que alternan con materiales históricos y testimoniales, incluso con documentación científica. El manejo de las fuentes aspira así a crear una obra "trans-genérica", que alíe historia y ficción (García Torres 2009: 303).

El arquitecto y el relojero (1999), El olvido está lleno de memoria (2002) y Las raíces cortadas (2003), fueron escritas durante la legislatura del Partido Popular, y por lo tanto, antes de que se votara la Ley de Memoria en 2007, que representa, a pesar de su tibieza, un jalón en el que la recuperación de ese pasado acallado y 
encallado (incluso encanallado por el discurso dominante), da lugar a un debate entre la "memoria de oposición" - como la denomina el propio López Mozo - y la "memoria dominante". Estas obras, junto con las muchas otras que alimentan la dramaturgia de la memoria a partir de los '90, se hacen eco y empujan por su temática poco consensual el debate que corre parejo a la acción asociativa intensificada también a partir del año 2000 (ARMH). Destaca, pues, una clara correspondencia entre la actividad civil y la artística, que da cuenta de la estrecha relación entre discurso político y creación dramática.

Singulariza a estas tres obras una perspectiva unitariamente crítica en torno a la revisión, hoy, del valor político de la transición que se dio ayer. De ahí que no se acartonen y que el destinatario de la obra escrita en 1999 encuentre un mensaje de rabiosa actualidad a día de hoy, pues la cuestión de la revisión de las responsabilidades del pasado y su impacto en el presente es un tema todavía no zanjado en España. En el siguiente cuadro se detallan las diferentes temporalidades que conforman el engarzado histórico y ficcional de las tres obras:

\begin{tabular}{|c|c|c|}
\hline $\begin{array}{l}\text { Escritura (publicación) } \\
\text { [puesta en escena] }\end{array}$ & Tiempo dramático & $\begin{array}{l}\text { Tiempos convocados/ } \\
\text { evocados }\end{array}$ \\
\hline $\begin{array}{l}\text { El Arquitecto y el Relojero } \\
1999 \\
(2000) \\
{[2006]} \\
\text { Premio Arniches }\end{array}$ & $\begin{array}{l}\text { Coetáneo (al tiempo de escritura) entre } 1995 \text { y } 1998 \\
\text { o"años posteriores a 1975" }\end{array}$ & $\begin{array}{l}\text { - Hechos heroicos Historia española } \\
\text { siglo XIX } \\
\text { - Franquismo } \\
\text { - 1977, transición }\end{array}$ \\
\hline $\begin{array}{l}\text { El olvido está lleno de } \\
\text { memoria } \\
2002 \\
(2003, A D E) \\
{[2003]}\end{array}$ & 1980: transición democrática & $\begin{array}{l}\text { - República } \\
\text { - Guerra } \\
\text { - Exilio } \\
\text { - Franquismo }\end{array}$ \\
\hline $\begin{array}{l}\text { Las raíces cortadas } \\
2003 \\
(2005) \\
{[2011,2013]}\end{array}$ & $\begin{array}{l}\text { (pre-transición) } \\
\text { - } 1973 \text { (anuncio de la muerte Clara Campoamor) } \\
\text { (pos-transición) } \\
\text { - } 1986 \text { y } 1987 \text { (muerte de Victoria Kent) } \\
\text { Momentos detonadores de evocación }\end{array}$ & $\begin{array}{l}\text { - Infancia, } \\
\text { - República (1931) } \\
\text { - Guerra, exilio } \\
\text { - Franquismo } \\
\text { - Tiempo inconexo: escenas de títeres }\end{array}$ \\
\hline
\end{tabular}

Como podemos constatar, destaca en el marco temporal una preponderancia de acontecimientos ubicados en y en torno al período de la transición democrática (1975-1982), lo cual no es anodino desde una perspectiva actual. La trilogía de Jerónimo López Mozo va a responder, pues, a una doble voluntad: primero, ser antídoto contra uno de los discursos historicistas nacionales afianzados durante la transición, es decir, contra la construcción del concepto de "empate histórico" que, custodiado por diversos pactos y por una amnistía consensual, evacúa la problemática de las responsabilidades penales, civiles y políticas sobre las exacciones cometidas durante y después de la guerra. Y, segundo, una reflexión sobre la conciencia identitaria y memorial del individuo fractal postmoderno para quien el trabajo de "memoria" se ve influenciado por una manera diferente de concebir la Historia, cuestionada ahora en tanto que discurso fundador de construcciones identitarias colectivas y/o nacionales. 


\section{Si el olvido es negación: El arquitecto y el relojero ${ }^{3}$}

De la trilogía sobre la memoria histórica, esta es la obra más depurada y estilizada, por no decir esencializada. Concebida con fina ingeniería dramática, se caracteriza por un lenguaje preciso y pautado por silencios o respiraciones dramáticas, en constante articulación con soportes audiovisuales diversos.

Se le encomienda a un arquitecto la rehabilitación de la antigua Casa de Correos sita en la Puerta del Sol de Madrid, la que fuera sede de la Dirección General de Seguridad durante el franquismo y es sede actual del Gobierno autonómico de Madrid. Un lugar, pues, preñado de Historia. El relojero es el encargado del mantenimiento del emblemático reloj de la torre. El arquitecto y el relojero (representaciones arquetípicas de una dialéctica ideológica), mantienen un pulso respecto al tratamiento que el edificio debiera hacer de su Historia reciente: para el primero, desprenderse de ella y transformar el lugar en una mera fachada, de aséptica modernidad; para el segundo, salvaguardarla, haciendo de ese lugar, o al menos de un rincón de ese lugar, un lugar de memoria, que no solo aluda a episodios histórico-patrióticos ennoblecedores (como la Guerra de la Independencia del siglo XIX), sino también a episodios menos gloriosos, como el del franquismo, en el que los sótanos, por ejemplo, sirvieron de sala de tortura. Portavoz de la memoria del tiempo pasado, el relojero es también el representante de ese "tiempo de la memoria" que reclama para el presente; y así guarda las pruebas fehacientes del pasado traumático: fichas, documentos, objetos como máquinas de escribir, grabadoras, barras de hierro, esposas, etc., pulcramente inventariados. Se plantea, pues, la siguiente cuestión: ¿cómo un lugar de Historia puede convertirse en un lugar de memoria, de conciencia memorial? John P. Gabriele, en un estudio sobre el valor de lo museístico aplicado a esta obra, sigue a Pierre Nora a la hora de responder a tal pregunta:

La resolución del Relojero de afincar la memoria materialmente afirma lo que postula Pierre Nora, que «la "memoria" se arraiga en lo concreto, en espacios, gestos, imágenes y objetos. [...] El museo tiene como fin conceptualizar espacialmente el tiempo y temporalizar el espacio con el fin último de evitar el olvido.» (Gabriele 2011).

Asimismo abunda en la obra un recurso recurrente de esta dramaturgia, que ya aparece como constante simbólica en la escritura histórico-teatral de Mozo desde su obra Guernica, con el emblemático personaje de La portadora de la lámpara: se trata de la luz, en su triple acepción, temática, escénica y simbólica. La luz vehicula un sentido de transparencia fútil y falaz: «Arquitecto. - Poeta de la luz y de la transparencia me han llamado» (p. 69); pero también es arma contra el ocultamiento y el olvido en pos de la elucidación de la verdad. Cristaliza

3 El arquitecto y el relojero, Madrid, AAT, 2001 (Premio Arniches 2000). Estrenada el 13 de noviembre de 2006, Muestra de Teatro, Alicante, Teatro Principal. También el 1 de febrero de 2007, en el Teatro Galileo de Madrid, con el mismo reparto: Gary Piquer (Arquitecto), Antonio Canal (Relojero), Juan Carlos González (Utilero). Dirección: Luis Maluenda. 
este tratamiento en la composición de los espacios dramáticos y escénicos, en los que se recuperan metafóricamente los claroscuros de la Historia que alberga el edificio de la Puerta del Sol y que remiten a menudo a las luces y sombras de la transición democrática:

Arquitecto.- Fue un acuerdo tácito de las fuerzas políticas durante la transición. Era aconsejable pasar la página y así se hizo. Oficialmente, no existen.

RELojero.- - Hay papeles y documentos que se resisten a desaparecer. Sobreviven a la hostilidad de los hombres y del tiempo. Piden salir a la luz, como estos.

ARQuitecto.- ¡Los papeles no piden nada!

Relojero.- Hablan por los muertos (p. 62).

La cúpula de cristal que coronará al edificio es la obsesión estética del arquitecto. En torno a este elemento se despliega la dialéctica, más que dualidad semántica, del significado que tiene o debe tener la luz para los dos personajes:

Arquitecto.- - [...] He querido dotar a este núcleo central del edificio de una intensa luminosidad, hacer que la luz, filtrada a través de una cubierta transparente, geometría de acero y de vidrio, resbale por las paredes. (p. 65).

ARquitecto.- Odio los espacios cerrados.

Por eso amo la arquitectura de cristal.

El vidrio refleja el cielo,

deja pasar la luz del sol,

es enemigo del misterio.

Suprime las sombras [...]

Bajo esta epidermis de cristal,

El hombre se sentirá otro. [...]

¿Cree que este recinto de esperanza es el sitio más indicado para instalar su habitáculo de pesadilla?

RELOJERO.- Quizás mejor que ningún otro.

A mí me gustan los edificios construidos con materiales que envejecen con las personas,

la madera,

el ladrillo,

la piedra...

El vidrio no envejece o lo hace tan despacio que apenas se aprecia.

Sin embargo, permite esparcir la luz sobre lo que hay al otro lado, verlo, ver, por ejemplo, la reconstrucción de la celda [...] no para que esos ciudadanos de nuevo cuño sufran pesadillas,

Sino para que nunca

Nadie

les hable de asuntos que desconocen. [...]

Algún día, $[\ldots]$

la película de polvo que se forme irá apagando la luz cenital,

La luz que usted quiere para su obra. (p. 68)

Del mismo modo, el lenguaje audiovisual aparece como otro vector de expresión de la materia memorial, aliando lo histórico-documental y 
lo ficticio mediante imágenes proyectadas en pantallas en las que pueden aparecer fotografías y documentos históricos junto con secuencias fílmicas de interrogatorios, en su día rodadas especialmente para el primer montaje, como expone López Mozo en otra entrevista que le hicimos en 2012:

Algunas de las imágenes proceden de materiales históricos, en concreto las siguientes: las proyecciones de dibujos y grabados de la escena CERO y la maquinaria del reloj que aparece en algunas ocasiones. Se trata de la maquinaria auténtica, que pudimos filmar con no pocas dificultades gracias a que nos dieron un permiso oficial.En cambio, todas las imágenes de la celda y de los interrogatorios fueron rodadas en una sala de ensayos con actores ${ }^{4}$.

Las técnicas del collage trans-semiótico de códigos gráficos, cinematográficos, fotográficos o plásticos, destacan en esta obra, ejemplar a la hora de mostrar la potencialidad del teatro como arte sincrético. Ante la cerrazón del arquitecto y de las autoridades que quieren sustituir el reloj, el relojero preparará el boicot de la inauguración del nuevo edificio. El ajuste de las agujas del reloj por parte del relojero predice el ajuste de cuentas de este (y del autor) hacia todos los "demócratas" que acuden al acto, arremetiendo contra los franquistas reciclados en demócratas, pero también contra los «demócratas a carta cabal (a quienes) no les importa estrechar las manos que un día les abofetearon o que firmaron los expedientes que les llevaron a la cárcel y a otros al pelotón» (p. 75). Al sonido de las doce campanadas, la esfera del reloj se desprende y arrasa la cúpula de cristal, cuya luz no sirve más que para deslumbrar y cegar al visitante:

Relojero.- El autor pone en mi boca algunas reflexiones sobre la arquitectura de cristal [...]. Reconoce que es hermosa [...]. Pero tanta luz y transparencia le provocan algunas dudas. Teme que, en ocasiones, el vidrio sea más opaco que el hormigón. [...] Deslumbra hasta convertir en invisibles los objetos que ilumina (p. 72-73).

Desde este coup de théâtre autorreferencial el mismo autor toma partido encarnando así el compromiso para con una "memoria de resistencia" opuesta a una cultura de la memoria escaparatista y mundana. El Relojero ejecuta al pie de la letra las instrucciones dadas por el AUTOR destruyendo la cúpula y arrojando al tiempo fotos, fichas y expedientes: « Lo que el relojero tira y los cristales rotos, regresa en forma de lluvia desde el telar» (p. 74). La disposición fragmentada de los espacios de ficción en un mismo espacio escénico produce un poético efecto de inmersión, tanto sonoro como visual, al ser el público testigo y casi receptor de los escombros en los que se convierte la cubierta de vidrio del edificio. Implicados visual y metafóricamente en el espacio superior habitado por el Relojero, también lo estamos en el inferior-interior, concebido por el arquitecto. El Arquitecto defiende una memoria selectiva, elitista y magnificadora en menoscabo de una memoria total, encarnada por el Relojero. Si el arquitecto encarna la gramática de la negación, el relojero simboliza la abnegación absoluta ante el deber de memoria.

4 Intercambio por correo electrónico con el autor en fecha del 1/10/2012. 
En paralelo, la presencia del utilero y el tramoyista, así como las instrucciones precisas del AUTOR, leídas y "puestas en acto" por el relojero, ambicionan un distanciamiento en el público, contrastado con la inmersión a la que también se le invita. Este vaivén entre la inmersión y la distanciación es uno de los rasgos característicos de la escritura dramática de López Mozo, impregnada de herramientas brechtianas que permiten desbaratar la manipulación a la que puede conducir la apariencia de realidad. Despuntan asimismo aquí elementos paradigmáticos del planteamiento estético de la Generación simbolista, singularizada por una concepción prístina del hecho teatral como acto ceremonial y ritual de la experiencia artística, sublimada en la iluminación de la verdad mediante el instrumento artístico de la mentira.

Tras el salto al vacío del relojero, el final queda abierto, el arquitecto despierta de lo que parece ser un extraño sueño, y vemos de nuevo a los dos personajes retomando el primer encuentro entre ellos. Esta circularidad sorpresiva permite al espectador llevarse "deberes para casa”, planteándose, a raíz de lo experimentado en el teatro, la posibilidad de reescribir la historia desde la conciencia de poder "volver a empezar" evitando los errores a los que puede conducir la negación del pasado.

\section{Si el olvido es muerte: El olvido está lleno de memoria ${ }^{5}$}

En primer lugar, cabe preguntarse por qué los comentarios críticos relativos a esta obra omiten aludir a la curiosa coincidencia entre el título de la misma y el de un poema homónimo de Mario Benedetti. El propio autor nos sacó de dudas al aclarar que él mismo desconocía tal coincidencia cuando aceptó espontáneamente la propuesta del título que le hizo un allegado. Tal coincidencia no sería más que anecdótica si no fuera porque la temática del poema redunda en la de la obra de teatro de López Mozo, conformando un diálogo de nuevo "trans-genérico" que sobrepasa los límites de lo canónicamente intertextual.

En El olvido está lleno de memoria, Jerónimo López Mozo recupera la persona de Edmundo Barbero, actor de renombre durante la República y el exilio, que vuelve a España en los primeros ' 80 . Vive con amargura la ignorancia de las nuevas generaciones, para quienes él es un perfecto desconocido, del mismo modo que han olvidado el porqué de su exilio. Julia Arroyo, joven

5 El olvido está lleno de memoria fue publicado por primera vez en la revista $A D E$ Teatro, 2003. Nosotros seguiremos en el presente trabajo la siguiente edición: Candyce Leonard y John P. Gabriele (eds.), Teatro español del siglo XXI: actos de memoria, Winston-Salem, Editorial Teatro, 2008. Estreno: 25 de abril de 2003, Sala Fernando de Rojas del Círculo de Bellas Artes, con el siguiente reparto: Francisco Merino (Edmundo Barbero), Chema Ruiz (Antolín Alvar) y Ainhoa Amestoy (Julia Arroyo), con dirección de Antonio Malonda. El vídeo que se proyecta con escenas de la obra La vida es sueño, de Calderón de la Barca, está interpretado por Rafael Esteban (Segismundo), Diana Facen (Rosaura), Miguel Álvarez (Clarín) y Bartomeu Ferrà (Regidor). 
periodista, pretende hacer un artículo sobre Barbero desde esa ignorancia. Entre ellos nace, a pesar del - o gracias al - desfase generacional, una intensa relación de transmisión testimonial, siendo la transmisión uno de los motivos centrales de la dramaturgia de la memoria. Antolín Alvar, empresario del teatro en el que trabaja Barbero, representa al arribista desaprensivo que, más que ignorar, reniega del pasado colectivo y personal (su padre, también vencido y exiliado, nunca volvió). La violencia de Alvar es la del resentido que, para avanzar, rechaza echar la vista atrás so pena de convertirse en estatua de sal. Encarna así el miedo a no poder integrar ese pasado traumático y quedarse encallado en lo que Laila Ripoll llama "los lodos" procedentes de los barros del pasado (Henríquez 2005). Un miedo enfundado de cinismo, con el que ataca a Edmundo:

Alvar. - ¿No te das cuenta de que más de media España nació cuando tú ya no estabas aquí? ¿Qué nos importan tus chismes? [...] Llegas tarde. El tío de América nos la trae floja. A callar y a trabajar. Es lo que toca...

BArbero.- - Trabajar, por supuesto. Pero callar... es matar los recuerdos. No sabía que tuvieras tan mala baba.

Alvar. - [...] Mírame. Fíjate en mí. España ha cambiado. No se parece ni por los forros a la que tú dejaste cuando cogiste las de Villadiego. Mientras hacías turismo por el Olimpo del exilio, aquí ya estábamos en el borrón y cuenta nueva. (p. 164-165)

[...]

¡Hijos de la grandísima puta! Ellos tuvieron su oportunidad. Fracasaron. Se fueron con el rabo entre las piernas, vivieron tan ricamente, esperando a que escampara para volver... Esta es nuestra hora, Julia, no la de ellos. No les necesitamos. Que se queden donde estaban. Y si vienen, como éste, quietos en un rincón y sin levantar la voz. (p. 172)

Tres generaciones (Barbero, Alvar, Julia), tres puntos de vista, unidos por el teatro, y en concreto por La vida es sueño, obra en la que trabaja Barbero, ya no como Segismundo, "emblema de la privación de identidad por razones políticas" (Fox 2004), sino en un papel secundario. Como lo subraya Manuela Fox, la metateatralidad intertextual vehicula la dicotomía entre el recuerdo y el olvido, alimentando asimismo la memoria literaria e histórica. La identidad de Barbero se irá deshilachando progresivamente, erosionada por una memoria averiada que le hace olvidar algunas réplicas de su último papel. Desde esa fragilidad, desgarrará la cuarta pared para interpelar directamente a un público también desdoblado: por una parte, un público de ficción que ha ido a ver $L a$ vida es sueño; por otra parte, el público del hic et nunc, a quien llegan, pues, los reproches emitidos por Barbero respecto a la responsabilidad ética de no olvidar. El dramatismo se intensifica al yuxtaponerse los estratos de ficción y realidad: Edmundo Barbero, desdoblado en un personaje de La vida es sueño, y que acaba hablando desde su doble identidad actor-personaje a un público implicado en la ficción e involucrado en la Historia.

El juego metateatral "rol into the rol" (Hornby 2006) pone así el acento en el polifacetismo de nuestra propia identidad como seres humanos. La identidad 
herida de Barbero es un frágil milhojas hecho de los diferentes papeles que ha ido habitando a lo largo de su vida teatral. Esos papeles "de papel" es lo poco que le queda al final de su vida cuando confiesa: « [...] he ido asumiendo, [...] ser menos de lo que soy.» (p. 187). Así lo apuntan, lúcidamente, Candyce Leonard y John P. Gabriele: « desempeñar papeles es vivir dichos papeles. Recordar el papel, es recordar a vivir [...]. En las obras de teatro, como en la vida, el individuo es el producto del intercambio constante entre más de un tiempo y más de un espacio.» (Leonard/Gabriele 2008: 4-5). Barbero pierde en su última función el control de su último papel, siendo este traspié metáfora de su declive como actor y como hombre.

Si en El arquitecto y el Relojero, López Mozo denuncia la continuidad del franquismo en la democracia mediante la institucionalización del olvido, en El olvido está lleno de memoria, se concentra sobre todo en los efectos de la amnesia. El paralelismo entre teatro y sociedad es claro: Barbero padece la pérdida de memoria, del mismo modo que el espectador-individuo experimenta los efectos del "gas letal" de la amnesia histórica al que se refería José Sanchis Sinisterra en aquellos años ' 80 explícitamente evocados por Barbero:

BARBERO. - ¿Saben que hubo una guerra civil? ¡La hubo! Esas caras... ¿Acaso lo dudan? Disculpo a los más jóvenes, aunque me sorprende su ignorancia. Alguien tendría que haberles hablado de ella [...] ¿Por qué no les han dicho nada? ¿Tal vez porque es algo remoto? ¿O, simplemente, la han olvidado? Me extraña... Los recuerdos perduran. Solo han pasado cuarenta años. ¿ $\mathrm{O}$ ha habido un pacto de silencio? (p. 186).

Barbero muere en las tablas del teatro. Patético, vencido y perdedor, su muerte debería sobrecogernos, pues en su agonía trágica, esos apóstrofes intencionados dirigidos a la sala son la transposición de tantas voces acalladas o dormidas, por fin recuperadas. Palabras contra el olvido, que es, como tantas veces se ha dicho ya, la segunda muerte de los muertos. Un sacrificio, una inmolación casi, en el altar de la memoria por excelencia, esto es el teatro - lugar sublimador de memoria -, para evitar que suceda lo que en su día anotara Eduardo Haro Tecglen: « [que la muerte] sea la ruina definitiva del futuro.» (Haro Tecglen 2003)

\section{Si el olvido es derrota: Las raíces cortadas ${ }^{6}$}

En esta obra, López Mozo recrea las vidas de Victoria Kent y Clara Campoamor, dos figuras pioneras en la lucha por los derechos de la mujer, entre ellos el del voto femenino, durante la II República. A pesar de tener puntos biográficos e ideales más que coincidentes, Victoria Kent (1889-1987) y Clara Campoamor (1888-1972) poco o nada se vieron o comunicaron a lo largo de sus vidas. A López Mozo le va a interesar lo que emerge entre los flecos de sus biografías

6 Las raíces cortadas, Madrid, AAT, 2005. Estrenada el 9 de diciembre de 2011 por la Compañía Off de Madrid, Teatro de la Sensación, en Ciudad Real. Dirección Luis Maluenda. Reparto: Pepa Sarsa (V. Kent) y Marisa Lahoz (C. Campoamor). 
oficiales, esos aspectos sobreentendidos o aludidos que son, al fin y al cabo, la mejor materia posible para recrear desde la ficción, sin la obsesión de la fidelidad histórica. Si el voto y el exilio son los mimbres temáticos de la obra, es sobre todo el tema del compromiso colectivo (y su reconocimiento o no por la Historia) el que destacaremos en estas páginas, pues en él radica la vigencia de un teatro hecho con lo que Buero Vallejo denominaba las "fórmulas fecundantes", gracias a las cuales una obra no caduca nunca. Se plantea, pues, restituir en la obra la complejidad de las vidas de las dos mujeres, proponiendo en conclusión una síntesis conciliadora de ambas trayectorias. Sin embargo, en este trabajo de elaboración artística, nuestro autor no pone tanto el acento en lo que separó a estas dos mujeres (la controversia en torno al voto femenino), sino en lo que hubiera podido reunirlas indefectiblemente, pues sus vidas compartían muchos puntos en común.

Como avanzábamos en la introducción, nos hallamos ante una obra cuya complejidad dialéctica rebasa el planteamiento arquetípico de El arquitecto y el relojero, así como el enfoque/choque transgeneracional de El olvido está lleno de memoria. En la tercera obra del tríptico sobre la memoria, López Mozo problematiza el motivo de la transmisión, del legado y de la responsabilidad del pasado para con el presente (tintes benjaminianos recurrentes en esta dramaturgia). Desde una perspectiva plural, aunque siguiendo en la pauta del enfrentamiento dialéctico entre dos personajes, el dramaturgo consigue sublimar la tesis y la antítesis en una suerte de síntesis final en la que se resuelven y disipan las dudas respecto a la utilidad del compromiso ciudadano y humano.

Ambos personajes, desdoblados, fragmentados, parodiados, autoparodiados, despliegan sus divergentes visiones políticas respecto al voto femenino en la II República y respecto al posibilismo de la resistencia ya desde dentro del país ya desde fuera, una vez declarada (y perdida) la guerra. Estos aspectos han sido harto abordados por la crítica (Doll, Fox, Gabriele García Torres); no obstante queda por desarrollar la problemática de la memoria desde la revisión crítica de la transición. Por ello, nos centraremos en los subtemas del desencanto, abordados en la obra a raíz del balance que hace al final de "su vida" Victoria Kent, y que nos sitúa significativamente en los años '80 (en concreto 1987), la década en la que se consolidó más (el espíritu de) la transición que la democracia. Acaso estos temas de corte político fueran los detonadores de la invisible censura que hizo mella en el devenir escénico de esta obra, según nos relata el propio autor:

A estos dos "incidentes" cabe añadir uno más reciente. Cuando publiqué Las raíces cortadas, Juan Antonio Hormigón me pidió los derechos para representarla. Contaba, en principio, con la ayuda de un Ministerio (creo que el de Asuntos sociales). Cuando les presentó el texto, se echaron atrás. Había algo en el contenido de la obra que no les parecía políticamente correcto. Nunca he sabido qué era lo no que no les gustó, pero intuyo que se trataba de algún comentario sobre la figura del Rey. He de reconocer que, salvo estos episodios, no he recibido ningún tipo de presión a la hora de abordar temas relacionados con la memoria histórica (ni con ninguna otra cuestión). Me refiero, claro está, a 
quienes han publicado las obras y a los que las han llevado a escena. Difícilmente podía producirse, pues siempre trabajo con personas amigas e ideológicamente afines. Otra cosa bien distinta, es que ellas, a la hora de ofrecer el espectáculo a teatros, programadores, instituciones, etc., lo hayan tenido fácil. Ahí, los rechazos han sido frecuentes y han venido, tanto de las administraciones públicas como de las empresas privadas. En el primer caso, generalmente por razones políticas o porque los gestores responsables de programarlas se "curan en salud" para no irritar a sus superiores. En el de las empresas privadas, hay un doble motivo: que no vean posibilidades de éxito comercial en este tipo de obras y el temor a que su programación dificulte la obtención de subvenciones. Hay que tener en cuenta que, en España, el $90 \%$ del teatro que se hace recibe ayuda pública. ${ }^{7}$ (Entrevista con López Mozo 12/09/2013).

La obra se divide en cinco "Encuentros apócrifos" que siguen la línea vital de Victoria Kent (Niñez-Muerte), salpicada de saltos temporales referenciales, lo cual dota a la obra de una estructura fragmentada y descoyuntada muy propia del canon postmoderno. Así, las coordenadas espacio-temporales se someten a la ruptura de la lógica ilusionista, lo que diferencia a esta obra de las dos anteriores. Por su parte, la escena es el único lugar de referencia espacial concreto, al aglutinar por yuxtaposición y simultaneidad todos los espaciostiempos evocados, convocados e imaginados (oficina de Victoria en Nueva York; teatrillo de marionetas; habitación de un hospital, etc.).

Entre varios saltos temporales $(1973,1931,1973)$ el autor introduce una escena de títeres en la que la clara (Campoamor) y la yema (Kent), aparecen como el hazmerreír de sus propios correligionarios parlamentarios, también guiñolizados, criticadas por sus elocuciones y gestualidades exaltadas, asimiladas a gallinas cacareantes (García Torres 2009: 310, 315 y ss.). Así, los mecanismos de distanciación que operan en esta obra no pasan, como en las dos anteriores, por la autorreferencialidad o la metateatralidad intertextual. Es el desdoblamiento, por un lado grotesco, vehiculado por la marionetización, y por otro identitario (como el que permite alternar entre las edades de Victoria en los años '70 y en los años '30 o como el que se concreta en la polifonía de voces del final), el mecanismo que permite romper con el efecto de realidad o la simple ilusión/restitución biográfica. Tal amalgama de géneros y registros, así como la

7 Cabe completar la visión del dramaturgo con otras declaraciones en las que matiza esta realidad condicionante de la creación: «Creo, sin embargo, que ese miedo es exagerado. Es posible que haya alguna excepción, pero mi experiencia personal me permite asegurar que, su concesión, depende más de otros parámetros que de los políticos. Obras mías, como El arquitecto y el relojero, Las raíces cortadas y El biógrafo amanuense fueron escritas con ayudas a la creación. Cuando Juan Carlos Pérez de la Fuente me encargó la escritura de Puerta del Sol, proyecto financiado por la Comunidad de Madrid, gobernada por el Partido Popular, aceptó que reflejara en ella mis puntos de vista sobre el Dos de Mayo, muy distintos a la versión oficial. Todo fue respetado en la puesta en escena y el único gesto de malestar fue que la presidenta de la Comunidad, Esperanza Aguirre, no asistió a ninguna representación.» (entrevista con López Mozo, 12/09/2013). 
desconstrucción de los personajes, se solapan en el discurrir de la acción en un continuum compacto, únicamente puntuado por los títulos que anuncian los "encuentros", enfocados desde la trayectoria vital de Victoria Kent.

Fiel a su manera de proceder, López Mozo esculpe a sus personajes a partir de un nutrido trabajo de documentación histórica (López Mozo 2005), en base al cual destila a lo largo de los cuatro encuentros apócrifos las complejas personalidades de ambas mujeres. El dramaturgo no duda en poner el acento en un momento clave de la vida de Victoria Kent (1973-1976) para mostrar la evolución de su posición respecto a los eventos de la transición democrática. Si en un principio se mostró férreamente fiel a sus convicciones republicanas (como emerge en la escena en la que defiende sin ambigüedades el color republicano de su revista Iberia, p. 64), a partir de la muerte de Franco empezó a observar con benevolencia el giro que tomaba el país y al artífice de tal logro. En 1986, el rey Juan Carlos I le concedió la Gran Cruz de la Orden de San Raimundo de Peñafort, patrón de los abogados, lo cual desencadena un acalorado debate (apócrifo, claro está) entre Victoria, halagada por tal reconocimiento, y Clara, quien, en su día, rechazara una condecoración de Alfonso XIII:

ClARA.- Suena a recompensa por haberte pasado a las filas de la Corona.

Victoria.- Toda mi vida he luchado para que España tuviese una democracia y ya la tiene. Mis anhelos políticos se han cumplido.

Clara. - ¿Qué ha sido de aquella fe en la República?

Victoria.- ¿Me lo preguntas tú, que la perdiste al primer contratiempo? La mantuve hasta el día mismo en que dejó de tener sentido, hasta que la victoria que soñábamos se convirtió en algo inalcanzable. Nada hay en mi conducta que pueda ser tachado de deshonroso o de indigno. ¿Qué vienes a echarme en cara? (Impide con un gesto que Clara la interrumpa.) He aceptado la solución monárquica porque he apostado por la concordia. Tenemos un rey sencillo y democrático. El muchacho lo está haciendo bien. Si garantiza las libertades esenciales, no pido más. Nunca he creído en la eficacia de la violencia. He sido y soy pacifista. Tal vez, en algún momento haya dado muestras de esa exaltación tan nuestra que tanto daño suele causarnos. No lo niego. Pero la madurez clarifica muchas cosas. Lleva la luz donde existía llama.

Clara.- Luz artificial.

Victoria.- ¡Luz! Y ahora, vete. No consiento que nadie me agüe la fiesta. Y menos tú.

(Las raíces cortadas, p. 73-74)

Cabe traer a colación la alusión a la luz, desprovista aquí de la forma dialéctica, que impregna a $E l$ arquitecto y el relojero (esclarecer/manipular). La luz metaforiza el apaciguamiento de la efusividad juvenil en la última edad de la vida, cuando hay que hacer balance de lo hecho. Y "lo hecho", el legado de su compromiso político, se reducirá, tras el balance, a la triste evidencia del vacío: Victoria y Clara aparecen en el quinto encuentro - 1987, en la habitación del hospital donde Victoria fallecerá - como dos derrotadas: "Somos dos perdedoras» (p. 87), dirá Victoria. La derrota como sentimiento de desencanto que acaso sea trasunto de aquel otro desencanto de los ' 80 : 
Clara. - Nunca antes te la había dado [la razón]. Pero no me duele hacerlo ahora. Tienes razón. El resultado de nuestra lucha no ha podido ser peor. Me pregunto si verdaderamente merece la pena hacer algo en la vida. Derroché pasión y vitalidad y, de repente, cuando todavía me sobraba energía [...] sucede algo terrible que me saca de mi ambiente. (p. 87-88).

Las dos "amigas" hacen balance de lo que han guardado en sus baúles del recuerdo, preguntándose qué hacer con ellos: enmarcarlos plastificarlos, archivarlos, destrozarlos, renegarlos, o bien, sacarles provecho. Son dos vencidas, pero, a pesar de cierto pesimismo, no se dan por vencidas; su desencanto no es claudicación - diferencia quizás con la melancolía desencantada de Edmundo Barbero. Aquí radica el valor del mensaje que transciende al espectador del siglo XXI, en palabras de Clara, que fue sin duda la más castigada por las circunstancias históricas y por sus elecciones políticas:

Clara.- [...] el fracaso está en que rememoremos aquellos hechos con amargura. Uno llega hasta donde los demás le dejan o sus fuerzas se lo permiten. Otros vienen después a continuar la tarea [...]. [...] nosotras hicimos a plena satisfacción nuestros deberes. Deberíamos estar orgullosas de ello y de nuestras cicatrices [...]. Trabajamos para el futuro, aunque no lleguemos a verlo. (p. 92)

El final de la obra, de gran efectismo poético, apuesta por una estampa visual, sin palabras, a partir de un dispositivo de pantalla en el que se proyecta una playa, cuya arena debe producir el efecto de semienterrar a las protagonistas. Personajes históricos conocidos y otros anónimos, van dejando sus huellas en una simbólica playa, al tiempo que las va borrando el mar y son sustituidas por otras huellas, otras pisadas, de otras figuras humanas, "que parecen desprendidas de un álbum de fotos» (p. 93). López Mozo firma así un final abierto, en el que la muerte se lleva definitivamente a las dos protagonistas de su historia y de nuestra Historia, dando paso a un mensaje que no por didáctico es menos eficaz: la Historia la hacemos todos, en tanto que seres colectivos construidos por nuestro pasado, pero es también la Historia la que nos hace y modela nuestro presente.

Jerónimo López Mozo nos alerta: si el olvido puede dar pie al negacionismo, a la manipulación y a la derrota - o derrotismo - de los ideales, la lucha por una memoria restituida, regenerada y dignificada debe ser, más que nunca, empeño colectivo. El compromiso, en definitiva, como clave del teatro lopezmociano: interpelar y, en palabras de John P. Gabriele, «enaltecer la conciencia» del espectador planteándole una reflexión sobre el valor y la responsabilidad del pasado en el presente, sobre la necesidad de construir una memoria justa como matriz de identidad colectiva. Para que la incultura no triunfe sobre la memoria.

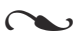




\section{Entrevista a Jerónimo López Mozo (12/09/2013), realizada por Antonia Amo Sánchez.}

\section{El compromiso contra la mentira histórica}

Antonia Amo Sánchez (A.A.S.): ¿Qué piensas de la dramaturgia sobre la memoria histórica que despunta a partir de los años 90/2000?

Jerónimo López (J.L.): No creo que haya sobresalido respecto a otras dramaturgias, pero sí que ocupa un lugar importante en la producción de estos años. Bastante más, desde luego, que en los años de la Transición. En mi opinión, el cambio empezó a producirse cuando los herederos de las víctimas de la guerra civil empezaron a exigir su rehabilitación y la anulación de las sentencias dictadas durante la posguerra por los tribunales de justicia del régimen franquista y, sobre todo, que se emprendiera la búsqueda de fosas comunes para devolverles los restos de los familiares enterrados en ellas. El hecho de que los poderes públicos no atendieran esas demandas o lo hicieran con tibieza destapó una ola de solidaridad que movilizó a sectores de izquierdas y grupos inquietos de nuestra sociedad. Su reflejo en los medios de comunicación y la actuación de determinados jueces progresistas que dieron importantes pasos para la reparación de los daños causados durante la guerra y primeros años de la dictadura han permitido mantener viva esa lucha. Los creadores han aportado su grano de arena y muchas de sus obras tienen que ver con todo cuanto cabe bajo el paraguas de la memoria histórica. La bibliografía de obras de ficción o que recrean hechos reales es notable. En el campo concreto del teatro no es una excepción. La solución a estas cuestiones avanza con gran lentitud. Las trabas de los que se resisten a revisar nuestro pasado y a reconocer la verdad histórica son enormes. Está todavía lejos el momento en que se haga justicia y las heridas cicatricen. En consonancia con ello, el de la memoria histórica, es un asunto que seguirá presente en la literatura actual. Es necesario que así sea. ¿Hasta cuándo? Al menos, hasta que el tema quede definitivamente cerrado, pero muy probablemente siga siendo motivo de reflexión durante algún tiempo más. Me lleva a pensar así que, con la incorporación de nuevos dramaturgos, el interés no ha decaído. Hablo del teatro, que es el medio que mejor conozco. Veo como jóvenes colegas abordan estos temas pertenecientes a un pasado que para algunos empieza a ser remoto.

(A.A.S.): ¿Alguna obra tuya comprometida con la verdad y justicia históricas ha sido "desechada" en los circuitos teatrales por motivos políticos durante la democracia?

J.L.: De mi relación con la censura excluyo el periodo franquista. Fue mala, pero no peor que la mantenida por buena parte de mis colegas. En la etapa democrática, las cosas mejoraron, sobre todo a raíz de que la Junta de Censura desapareciera. Empezaron entonces otras formas de censura encubierta y más sutil, cuya documentación no resulta fácil. Antes, la prohibición de las obras quedaba recogida en un documento del Ministerio de Información y Turismo en 
el que figuraban los artículos del reglamento de censura en que se fundamentaba el rechazo. Ahora no existen papeles. Los vetos se producen de forma verbal y, a menudo, los argumentos que se ofrecen no son los reales. Me estoy refiriendo a la censura política o ideológica, pero existen otras de tipo económico (número de personajes, dificultades escenográficas y atractivo comercial de los temas abordados) que, quizás, no sean relevantes para tu trabajo.

Respecto a mi experiencia personal, los dos casos de censura más llamativos son los que mencioné en un artículo publicado en 2012 en la revista digital Anagnórisis.

Al cabo, recuperé mi ritmo habitual sin que hubiera más motivos para ello que mi voluntad de seguir escribiendo contra viento y marea. Ni siquiera dos acontecimientos adversos tuvieron fuerza suficiente para hacerme desistir. En ambos anduvo por medio la censura, no la oficial, que había desaparecido, sino otra encubierta que cuestionaba la idea de que, con la llegada de la democracia, habíamos alcanzado un grado de libertad de expresión plena.

El primer chasco llegó tras el estreno de Comedia de la olla romana en que cuece su arte la Lozana. La escribí por encargo de César Oliva, que había sido nombrado director de la compañía Corral de Almagro, creada bajo el patrocinio del Ministerio de Información y Turismo. Sin que nadie me lo dijera, poco después de iniciada la gira sospeché que mi trabajo no había gustado a los gerifaltes del Ministerio. En efecto, consideraban que la obra era, cuando menos, irreverente. No debió parecerles bien que me pusiera claramente del lado de la Lozana frente al poder establecido ni que me sirviera de ella, que no era, a sus ojos, más que una vulgar prostituta, para entonar un canto a lo lúdico frente al oscurantismo de un poder represor y corrupto. La gota que colmó el vaso fue una escena en la que Lozana se entrevista con el Papa y lo hace sentada sobre sus rodillas. La inquina oficial, espoleada por las quejas de algunos espectadores escandalizados, se hizo evidente cuando, en vísperas de que el espectáculo llegara a Madrid, fue retirado de la programación sin que se diera ninguna explicación.

El otro contratiempo se produjo en 1979 con Anarchia 36, obra que gira en torno a nuestra Guerra Civil. Había sido propuesta al Centro Dramático Nacional por Alberto Miralles, miembro del Comité de Lectura. Adolfo Marsillach me dio la noticia de que había sido aceptada y que, en consecuencia, sería estrenada en la temporada siguiente. Días después, hizo pública la programación. La obra no figuraba en ella. Supe de forma extraoficial que había sido eliminada porque, aun tratándose de un alegato contra el levantamiento militar franquista, alguien le había convencido de que no era bueno apostar por un texto en el que, al analizar las responsabilidades de comunistas y anarquistas en la derrota, yo me mostraba a favor de estos. (Anagnórisis, no 6 , diciembre 2012, testimonies, p. 1-17)

A estos dos "incidentes" cabe añadir uno más reciente. Cuando publiqué Las raíces cortadas, Juan Antonio Hormigón me pidió los derechos para representarla. Contaba, en principio, con la ayuda de un Ministerio (creo que el de Asuntos sociales). Cuando les presentó el texto, se echaron atrás. Había algo en el contenido de la obra que no les parecía políticamente correcto. Nunca he sabido qué era lo no que no les gustó, pero intuyo que se trataba de algún comentario sobre la figura del Rey. 
He de reconocer que, salvo estos episodios, no he recibido ningún tipo de presión a la hora de abordar temas relacionados con la memoria histórica (ni con ninguna otra cuestión). Me refiero, claro está, a quienes han publicado las obras y a los que que las han llevado a escena. Difícilmente podía producirse, pues siempre trabajo con personas amigas e ideológicamente afines. Otra cosa bien distinta, es que ellas, a la hora de ofrecer el espectáculo a teatros, programadores, instituciones, etc., lo hayan tenido fácil. Ahí, los rechazos han sido frecuentes y han venido, tanto de las administraciones públicas como de las empresas privadas. En el primer caso, generalmente por razones políticas o porque los gestores responsables de programarlas se "curan en salud" para no irritar a sus superiores. En el de las empresas privadas, hay un doble motivo: que no vean posibilidades de éxito comercial en este tipo de obras y el temor a que su programación dificulte la obtención de subvenciones. Hay que tener en cuenta que, en España, el 90 \% del teatro que se hace recibe ayuda pública. Creo, sin embargo, que ese miedo es exagerado. Es posible que haya alguna excepción, pero mi experiencia personal me permite asegurar que su concesión depende más de otros parámetros que de los políticos. Obras mías, como El arquitecto y el relojero, Las raíces cortadas y El biógrafo amanuense fueron escritas con ayudas a la creación. Cuando Juan Carlos Pérez de la Fuente me encargó la escritura de Puerta del Sol, proyecto financiado por la Comunidad de Madrid, gobernada por el Partido Popular, aceptó que reflejara en ella mis puntos de vista sobre el Dos de Mayo, muy distintos a la versión oficial. Todo fue respetado en la puesta en escena y el único gesto de malestar fue que la presidenta de la Comunidad, Esperanza Aguirre, no asistió a ninguna representación.

Respecto a la autocensura, nunca la he practicado, al menos de forma consciente. No lo hice durante el franquismo. Entonces, elegí escribir sin trabas y refugiarme en los circuitos alternativos, en los que había algunas posibilidades de burlar el control de la censura. Ahora, con una sola excepción, tampoco la practico. No veo motivos para ello. La excepción se produce cuando escribo una obra de encargo para compañías con limitados recursos materiales. En tales casos me adapto a sus posibilidades de producción. Nada tiene que ver, pues, con cuestiones políticas.

(A.A.S.): ¿Crees que existe un público especialmente sensible a esta temática?

J.L.: Las obras que abordan la memoria histórica no suelen atraer a demasiado público. Aunque ahora hay un bajón en la asistencia a espectáculos teatrales a causa de la crisis económica, en el pasado reciente las recaudaciones han crecido de año en año. Sin embargo, no todo el teatro se ha beneficiado en la misma medida de tal bonanza. Los mayores llenos se dan en los grandes musicales. Fuera de ellos, la escala del éxito la encabeza el prestigio de los actores y, sobre todo, la fama adquirida por su presencia en series televisivas. Sigue el interés que despierte la obra, que suele ser mayor cuando se trata de comedias divertidas, versiones escénicas de novelas famosas y dramas de autores extranjeros que vienen avalados por el éxito en los países de origen. También atraen los grandes 
montajes de los centros dramáticos y, curiosamente, el teatro clásico que ofrece la Compañía Nacional de Teatro Clásico. En honor a la verdad, hay que decir que algunos autores españoles ocupan lugares importantes en las carteleras con obras de gran calidad e interés, pero se trata de una feliz excepción. Todo este quizá innecesario preámbulo viene a cuento para decir que el teatro al que nos estamos refiriendo es minoritario. Minoritario, pero necesario. No tiene gran capacidad de convocatoria en la escena comercial, pero no es despreciable el número de personas que se sienten atraídas por él. Su espacio natural son las salas alternativas.

Sobre el público interesado en la memoria histórica debo decir que, en lo que a mí respecta, me siento satisfecho con su respuesta. No es exaltada, como sucedía durante el franquismo y primeros años de la transición, cuando el teatro comprometido cumplía, además de su función artística, la de servir de tribuna política. La complicidad entre creadores y receptores no se exterioriza ahora de la misma manera. Hoy, los ciudadanos tienen muchos más cauces para expresarse y desahogarse. Pero la comunión con el público se mantiene. Puedo dar fe de ello. En las representaciones a las que he asistido de mis propias obras he vivido momentos conmovedores. En una representación de Guernica en Nueva York, una anciana me contó que había nacido en esa ciudad y había sufrido su bombardeo. En otros casos he visto llorar a espectadores ancianos que vivieron los años de la República y la Guerra Civil y muchos, al saber que yo estaba entre el público, me han buscado para abrazarme y contarme cómo vivieron ellos aquel período. En una representación de Las raíces cortadas en el Ateneo de Madrid fui obsequiado con un ramo de flores cuyos colores reproducían la bandera republicana. Pero, a este emotivo archivo de la nostalgia, se añade otro alimentado por gente joven que no solo no vivió aquella etapa, sino que poco o nada sabía de lo sucedido en ella. Despertar su interés es uno de los objetivos de la recuperación de la memoria histórica. La respuesta recibida me anima a seguir empeñado en esa tarea.

\section{Bibliografía}

Amo Sánchez A., 2014, «Dramaturgias de lo imprescriptible: un teatro para la recuperación de la memoria histórica en España (1990-2012)», ALEC, 39.2, p. 337-365.

Doll E., 2008, El papel del artista en la dramaturgia de Jerónimo López Mozo: juegos temporales e intermediales, Madrid, Iberoamericana/Vervuert.

Floeck W., 2006, «Del drama histórico al teatro de la memoria. Lucha contra el olvido y búsqueda de identidad en el teatro español reciente», dans Tendencias escénicas al inicio del siglo XXI, Madrid, Visor Libros, p. 187-209.

Fox M., 2004, "La memoria histórica de Mozo», La ratonera, 11, p. 36-46, $<$ http://www.la-ratonera.net/numero11/n11_mozo.html>. 
Fox M., 2009, "Victoria Kent y Clara Campoamor en Las raíces cortadas de Jerónimo López Mozo », dans José Romera Castillo (éd.), El personaje teatral: la mujer en las dramaturgias masculinas en los inicios del siglo XXI, Madrid, Visor Libros, p. 187-198.

Gabriele J. P., 2007, «Metateatro y mnemotécnica: convenciones posmodernistas en El olvido está lleno de memoria, de Jerónimo López Mozo», Alpha, 25, p. 101-114.

Gabriele J.P., 2009a, Los dramaturgos hablan, Madrid, KRK.

Gabriele J.P., 2009b, Jerónimo López Mozo: forma y contenido de un teatro experimental, Madrid, Fundamentos.

Gabriele J.P., 2011, «El discurso mnemónico-museístico en El arquitecto $y$ el relojero de López Mozo», La ratonera, 32, p. 132-136, <http://www. la-ratonera.net $/ \mathrm{p}=800>$.

García Martínez, A., 2016, El telón de la memoria. La guerra civil y el franquismo en el teatro español actual, Hildesheim-Zürich-New York, Olms.

García Torres E., 2009, «Teatro de la memoria: Victoria Kent, Clara Campoamor y Las raíces cortadas, de Jerónimo López Mozo», Signa, 18, p. 299-319.

Guzmán, A., 2015, «Los albores de la meta-memoria histórica en el teatro español», Revista canadiense de estudios hispánicos, 40.1, p. 133-155.

Haro Tecglen E., 2003, "El olvido está lleno de memoria», El País.

Henríquez J., 2005, «Entrevista con Laila Ripoll», Primer Acto, 310, p. 118-127.

Hornby R., 1986, Drama, Metadrama and Perception, London/Toronto, Associated University Press.

Kumor, K., 2017, «El teatro de Jerónimo López Mozo como espejo del teatro español» dans Urszula Aszyk et alii, El teatro como espejo del teatro, Madrid, Verbum, p. 139-153.

Leonard C. y Gabriele J.P., 2008, Teatro español del siglo XXI: actos de memoria, Winston-Salem, Editorial Teatro.

López Mozo J., 1999, «Teatro y silencio», ALEC, 24, p. 679-688.

López Mozo J., 2012, «Testimonios», Anagnórisis, 6, p. 1-17.

Miralles A., 1982, «Escribir en libertad», Primer Acto, 195, p. 112-115.

Vilches de Frutos M.F., 2001, «Los meandros de la censura: una entrevista con Jerónimo López Mozo», Iberoamericana, 2, p. 189-195. 